\title{
Effect of lower limb dominance on walking adaptations in young adults when stepping into a hole
}

\author{
LUCIANA O. SANTOS ${ }^{1,2}$ | ANDRÉIA A. S. COSTA ${ }^{1,2}$ | RENATO MORAES ${ }^{1,2}$ |
}

1 Biomechanics and Motor Control Lab, School of Physical Education and Sport of Ribeirao Preto, University of Sao Paulo, São Paulo, SP, Brazil.

2 Graduate Program in Rehabilitation and Functional Performance, Ribeirão Preto Medical School, University of São Paulo, Ribeirão Preto, SP, Brazil.

Correspondence to: Renato Moraes, Ph.D., Associate Professor, Av. Bandeirantes, 3900, Ribeirão Preto, SP, 14040-907, BRAZIL, +55 $163315-0522$.

email: renatomoraes@usp.br

https://doi.org/10.20338/bjmb.v13i5.141

\section{HIGHLIGHTS \\ - There was asymmetry between dominant and non-dominant legs when stepping into a hole. \\ - Changes in walking parameters were consistent with safety considerations. \\ - The differences between dominant and non- dominant legs did not affect task success.}

\section{ABBREVIATIONS}

AP anterior-posterior

BW body weight

GRF ground reaction force

PUBLICATION DATA

Received 15072019

Accepted 06092019

Published 01122019

\begin{abstract}
BACKGROUND: Walking in the presence of a hole is a challenging task that demands appropriate adaptation for successful performance. Depending on the dimensions of the hole, characteristics of the walking surface and position of the hole relative to normal walking, individuals may need to step into the hole with the dominant or non-dominant limb.

AIM: We investigated the effect of lower limb dominance on walking adaptations in the presence of a hole in the ground.

METHOD: Twenty young adults walked and stepped into a hole positioned in the middle of the pathway using the dominant and non-dominant lower limbs.

RESULTS: For the trailing limb, the impulses were not affected by lower limb dominance, but for the leading limb, the non-dominant leg increased the braking and propulsive impulses compared to the dominant leg. On the other hand, toe-off velocity increased when the non-dominant limb was used as trailing and leading limbs. Stride speed increased when the non-dominant leg was the trailing limb.

CONCLUSION: Our results were consistent with asymmetrical behavior between dominant and non-dominant legs, but this difference was not enough to affect task success.
\end{abstract}

KEYWORDS: Avoidance strategy| Accommodation strategy| Gait | Obstacle | Step down

\section{INTRODUCTION}

We modify our gait pattern when walking on uneven terrains, using mechanisms that ensure dynamic stability to achieve the intended goal. ${ }^{1,2}$ To deal with rough terrains, individuals may use two strategies: avoidance or accommodation. ${ }^{3}$ The avoidance strategy involves the regulation of global parameters of walking to avoid undesirable areas, people, and objects that obstruct or disturb the walking, stop the locomotion, or overcome obstacles when possible. Different authors have investigated the avoidance of a planar obstacle on the ground, $, 2,4,5,6,7,8,9,10$ which is similar to avoiding a real hole in the ground. ${ }^{11}$ However, depending on the dimensions of the hole, characteristics of the walking surface, and position of the hole relative to normal walking, there may be a need to step into the hole. The adjustment of specific features of the walking pattern to adapt to the environment (e.g., the hole) defines the accommodation strategy. Although avoidance of an undesirable area on the ground has been extensively investigated, the accommodation strategy to step into a hole has been less studied. Thus, it is necessary to examine how the accommodation strategy is implemented in daily tasks, such as walking in the presence of a hole, which is very common in sidewalks, particularly in Brazil.

The first component of the task of stepping into a hole with one of the limbs is similar to the task of descending a stair. However, in the task of stepping into the hole, the stepping up from the hole component immediately follows the stepping down into the hole. 
This difference imposes different demands on these two tasks. We defined the limb that steps into the hole as the leading limb and the limb that does not step into the hole as the trailing limb. The adjustments are asymmetrical between the limbs since only one limb steps into the hole, and the force production and movement execution of the leading and trailing limbs can be affected by lower limb dominance. Previous studies showed that there is asymmetry between the dominant and non-dominant legs in some walking parameters, even in healthy individuals walking on unobstructed terrains. ${ }^{12}$ Some studies reinforce this asymmetry in adaptive locomotion. Young and older adults increased foot elevation for the non-dominant limb compared to the dominant limb in an obstacle avoidance task. ${ }^{13}$ Young adults decreased the foot-obstacle distance when using the non-dominant limb as the trailing limb. ${ }^{14}$ Moreover, the success rate was higher for stepping on targets that changed position on the ground when using the dominant compared to non-dominant limb. ${ }^{15}$

Although gait asymmetry can arise from lower limb dominance, lower limb strength imbalance could also explain gait asymmetry. Laroche et al. showed that strength asymmetry increased walking asymmetry in older adults. ${ }^{16}$ However, a recent systematic review was unable to provide further support for the relationship between gait asymmetry and muscular performance. ${ }^{17}$ Thus, we opted to focus the present study on the effect of lower limb dominance on walking adaptations when stepping into a hole.

Prior studies investigating walking adaptations to step into a hole did not consider lower limb dominance. For instance, Muller et al. showed that young adults decreased the second peak of the vertical ground reaction force for the trailing limb, and flexed the ankle and knee joints more at the end of the stance phase for the same limb compared to level walking. ${ }^{18}$ When stepping into the hole, there was an increase in the first peak of the vertical ground reaction force. ${ }^{18}$ These findings indicate that adjustments occurred not only at the perturbed contact but also one step before it. ${ }^{18}$ Aminiaghdam et al. showed that the margin of stability in the anterior-posterior (AP) direction reduced when stepping into the hole, which may compromise dynamic stability. ${ }^{19}$

Walking in the presence of a hole is a challenging task that demands appropriate adaptation for successful performance. Investigation of lower limb asymmetries in this task can serve as a basis for future studies interested in examining the effect of pathologies in walking, particularly pathologies that develop unilaterally. We investigated the effect of lower limb dominance on walking adaptations in the presence of a hole in the ground. The braking and propulsion impulses, foot velocity, and spatiotemporal stride parameters of both leading and trailing limbs were analyzed. These parameters allowed us to gather information about force modulation, limb end-point control to deal with the hole, and foot control when it is moving toward and away from the hole. Prior studies have suggested that there is task specificity related to lower limb dominance. ${ }^{12,20}$ When acting towards a goal, individuals perform the goal with the dominant limb, while the non-dominant limb provides support. Based on this assumption, we expected to find better control for the nondominant than for the dominant limb when the non-dominant limb was used as the trailing limb. On the other hand, for the leading limb, we expected to find better control when stepping into the hole with the dominant than with the non-dominant limb. 


\section{METHODS}

\section{Participants}

Twenty young adults participated in this study (8 women and 12 men, $24.9 \pm 3.7$ years, $78.8 \pm 15.7 \mathrm{~kg}, 177.2 \pm 11.7 \mathrm{~cm}$ ). The exclusion criteria were visual impairments not corrected by eyeglasses or contact lenses, severe neuromuscular, musculoskeletal, or cardiopulmonary disorders, and absence of lower limb dominance. The research ethics committee approved the experimental procedures, and participants signed a consent form.

\section{Procedures}

Participants responded to the Waterloo Footedness Questionnaire to determine lower limb dominance. ${ }^{21}$ The score varies from -20 to +20 . Scores between -20 and -7 indicate left dominance, between -6 and +6 mixed dominance, and between +7 and +20 right dominance. Next, the participants started the experiment, which consisted of walking on a pathway (length: $9 \mathrm{~m}$ | width: $6 \mathrm{~m}$ | height: $0.16 \mathrm{~m}$ ) that had a hole (length: $0.60 \mathrm{~m}$ | width: $0.80 \mathrm{~m}$ | depth: $0.12 \mathrm{~m}$ ) in the middle of it (Figure 1). The experimenter explained the task to the participant. After this initial explanation, the participant performed one trial for each condition to ensure that they understood the task. The participants were informed that they should walk at their preferred speed, should not stop before the hole, and should keep walking after stepping into the hole. The participants performed 20 randomized trials using the dominant (10 trials) and non-dominant (10 trials) limbs to step into the hole (leading limb). The trailing limb, which did not step into the hole, landed on a target region (a piece of paper with borders taped on the ground - length: $0.30 \mathrm{~m}$ | width: $0.21 \mathrm{~m}$ ) located close to the hole (Figure 1). The target region corresponded to one-step length relative to the center of the hole and was included to ensure that participants stepped into the hole.

The initial position was pre-determined and adjusted for each participant. The limb that initiated gait in each trial depended on which leg (dominant or non-dominant) was required to step into the hole. Two force plates (FP4060-NC, Bertec, Columbus, Ohio, USA) were positioned side-by-side in the target region and leveled to the pathway height. These force plates collected the ground reaction force (GRF) data of the trailing limb, depending on which limb stepped into the hole. Another force plate (AMTI AccuGait, Watertown, MA, USA) was positioned beneath the hole. The force platform signals were sampled at $100 \mathrm{~Hz}$. Three passive retro-reflective markers were placed on each foot (lateral malleolus, fifth metatarsal, and lateral face of the calcaneus), which were tracked by eight cameras (MXT-40S, Vicon, Oxford, United Kingdom), and sampled at $100 \mathrm{~Hz}$.

\section{Data analysis}

GRF was normalized by the body weight and used to calculate the braking and propulsion impulses in the anterior-posterior (AP) and vertical directions. We identified the foot contact and toe-off events when the vertical component of the GRF was $>5 \mathrm{~N}$ and $<5$ $\mathrm{N}$ after the initial contact on the force plate, respectively. The transition between braking and propulsion phases corresponded to the zero-crossing point in the GRF in the AP direction. We computed the impulse (area under the GRF curve) for the braking (from foot contact to zero-crossing) and propulsion (from zero-crossing to toe-off) phases.

\begin{tabular}{l|l|l|l|ll}
\hline $\begin{array}{l}\text { Santos, Costa, } \\
\text { Moraes }\end{array}$ & 2019 & VOL.13 & N.5 & https://doi.org/10.20338/bjmb.v13i5.141
\end{tabular}


Brazilian Journal of Motor Behavior
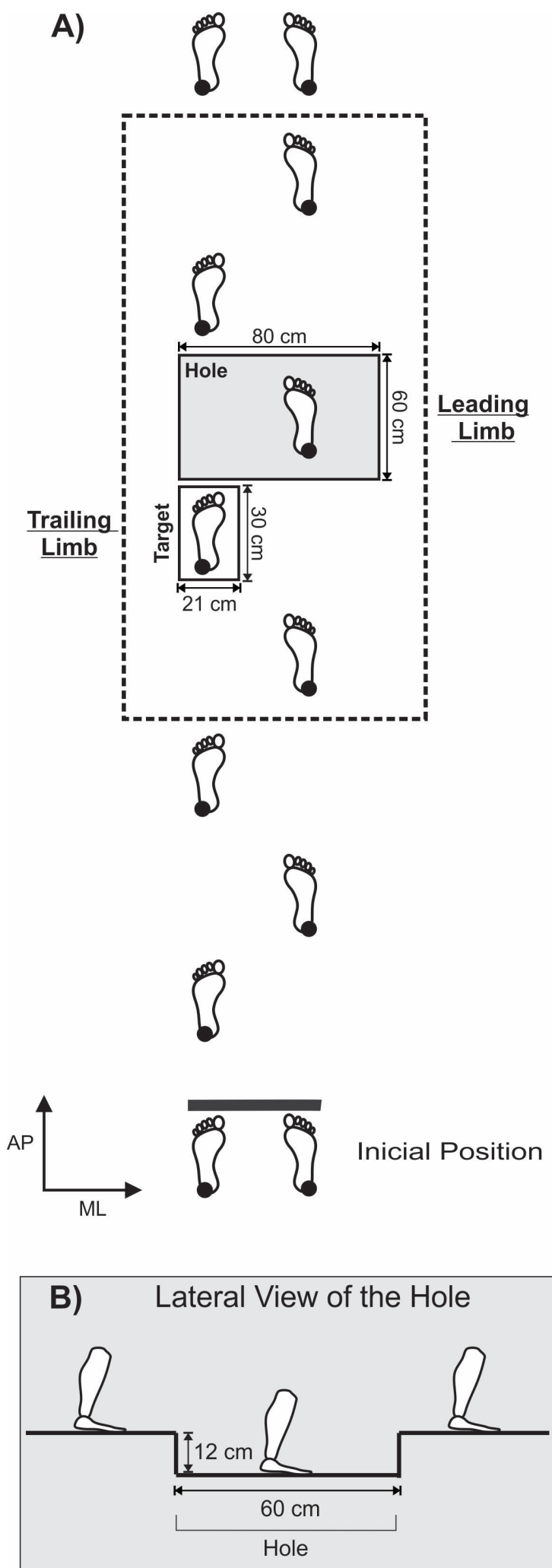

Figure 1. (A) Top view of the experimental setup. The blank rectangle represents the target region where participants stepped before stepping into the hole. The gray rectangle represents the location of the hole, illustrating only the condition where the right limb is in the hole. (B) Lateral view of the hole and its dimensions. 
The coordinates of the feet markers were digitally filtered using a fourth-order Butterworth low-pass digital filter with a cut-off frequency of $6 \mathrm{~Hz}$. Foot velocity was obtained as the first derivative relative to the time of the marker position (metatarsus) in both AP and vertical directions. Based on the foot velocity time series, we identified the toe-off velocity for the trailing and leading limbs. For the trailing limb, the toe-off velocity was measured when the leading limb was in the hole. For the leading limb, the toe-off velocity was measured when the foot was leaving the ground before stepping into the hole.

Some participants stepped initially into the hole using either a tiptoe or heel strategy, so the calculation of stride length used the instant when the foot was flat on the ground. Even after stepping into the hole using the tiptoe strategy, the participants always landed the rest of the foot on the ground. The stride length was calculated for the leading and trailing limbs as the difference between the coordinates of the calcaneus marker on the $y$-axis (AP) for successive contacts of the same limb on the ground. The stride duration was calculated as the time interval from the contact of the foot on the ground (tiptoe or heel, whichever occurred first) to the subsequent contact of the same foot on the ground. The stride speed was calculated by dividing the stride length by its corresponding duration. For the trailing limb, we used the stride correspondent to the period that the leading limb was in the hole, whereas for the leading limb, we used the stride correspondent to the period that the limb was moving towards the hole.

\section{Statistical analysis}

The average value of the ten trials per condition was used in the following statistical analyses. For the impulses and foot velocities, we performed one-way MANOVAs (limb [dominant and non-dominant]) with repeated measures. For these MANOVAs, we grouped the dependent variables using the AP and vertical directions. For the remaining variables, we ran one-way ANOVAs (limb [dominant and non-dominant]) with repeated measures. The level of significance was set at $\alpha \leq 0.05$.

\section{RESULTS}

\section{Lower Limb Dominance}

The score in the Waterloo Footedness Questionnaire ranged from +8 to +20 . The mean was 15.6 points $( \pm 4.5)$. Thus, all participants screened exhibited right lower limb dominance, and none of them were excluded because of a lack of lower limb dominance.

\section{Impulses}

Training Limb

For the braking impulse, although the MANOVA identified an effect of limb $(p=0.035)$, the univariate tests did not identify any effect in either AP or vertical directions. For the propulsion impulse, the MANOVA did not detect an effect of limb (Table 1).

\section{Leading limb}

The MANOVA identified an effect of limb $(p \leq 0.0001)$ for the braking impulse, and the univariate test identified this effect only in the AP direction $(p=0.001$, Table 1). For the propulsion impulse, the MANOVA also identified an effect of limb ( $\leq \leq 0.0001)$, and the 
Brazilian Journal of Motor Behavior

univariate test exhibited this effect only in the AP direction ( $\leq \leq 0.0001$, Table 1). Both impulses were higher for the non-dominant than for the dominant limb.

Table 1 - Mean and standard deviation (in brackets) for the impulses of the trailing and leading limbs. The two right columns indicate the differences observed in the statistical analyses.

\begin{tabular}{|c|c|c|c|c|}
\hline & \multicolumn{2}{|c|}{ Limbs } & \multirow{2}{*}{$\begin{array}{c}\text { MANOVA \& } \\
\text { Univariate Tests }\end{array}$} & \multirow[b]{2}{*}{ Differences } \\
\hline & Dominant & $\begin{array}{c}\text { Non- } \\
\text { Dominant }\end{array}$ & & \\
\hline \multicolumn{5}{|l|}{ Trailing Limb } \\
\hline Braking Impulses (BW.s) & & & $\begin{array}{c}\text { Wilks' } \lambda=0.689 \\
F_{2,18}=4.068, p=0.035\end{array}$ & \\
\hline AP Direction & $\begin{array}{l}-0.030 \\
(0.007)\end{array}$ & $\begin{array}{l}-0.029 \\
(0.007)\end{array}$ & $F_{1,19}=0.619, p=0.441$ & --- \\
\hline Vertical Direction & $\begin{array}{l}0.315 \\
(0.054)\end{array}$ & $\begin{array}{c}0.330 \\
(0.082)\end{array}$ & $F_{1,19}=1.319, p=0.265$ & --- \\
\hline \multicolumn{2}{|l|}{ Propulsion Impulses (BW.s) } & & $\begin{array}{c}\text { Wilks' } \lambda=0.848, \\
F_{2,18}=1.610, p=0.227\end{array}$ & \\
\hline AP Direction & $\begin{array}{c}0.034 \\
(0.007)\end{array}$ & $\begin{array}{c}0.035 \\
(0.008)\end{array}$ & $F_{1,19}=0.292, p=0.595$ & --- \\
\hline Vertical Direction & $\begin{array}{c}0.267 \\
(0.042)\end{array}$ & $\begin{array}{c}0.283 \\
(0.046)\end{array}$ & $F_{1,19}=3.306, p=0.085$ & --- \\
\hline \multicolumn{5}{|l|}{ Leading Limb } \\
\hline Braking Impulses (BW.s) & & & $\begin{array}{l}\text { Wilks' } \lambda=0.414, \\
F_{2,18}=12.735, \\
\mathbf{p} \leq \mathbf{0 . 0 0 0 1}\end{array}$ & \\
\hline AP Direction & $\begin{array}{l}-0.015 \\
(0.005)\end{array}$ & $\begin{array}{l}-0.019 \\
(0.004)\end{array}$ & $F_{1,19}=15.243, p=0.001$ & $\begin{array}{c}\text { Non-Dominant }> \\
\text { Dominant }\end{array}$ \\
\hline Vertical Direction & $\begin{array}{c}0.321 \\
(0.055)\end{array}$ & $\begin{array}{c}0.302 \\
(0.046)\end{array}$ & $F_{1,19}=2.607, p=0.123$ & --- \\
\hline Propulsion Impulses (BW.s & & & $\begin{array}{c}\text { Wilks' } \lambda=0.350 \\
F_{2,18}=16.733 \\
\mathbf{p} \leq \mathbf{0 . 0 0 0 1}\end{array}$ & \\
\hline AP Direction & $\begin{array}{c}0.014 \\
(0.006)\end{array}$ & $\begin{array}{c}0.019 \\
(0.006)\end{array}$ & $\begin{array}{c}F_{1,19}=30.335 \\
\mathbf{p} \leq \mathbf{0 . 0 0 0 1}\end{array}$ & $\begin{array}{c}\text { Non-Dominant }> \\
\text { Dominant }\end{array}$ \\
\hline Vertical Direction & $\begin{array}{c}0.256 \\
(0.091)\end{array}$ & $\begin{array}{c}0.256 \\
(0.062)\end{array}$ & $F_{1,19}=0.001, p=0.972$ & --- \\
\hline
\end{tabular}

BW: body weight | AP: anterior-posterior direction

Bold $p$-values indicate a significant effect of limb.

\section{Toe-off velocity}

Trailing Limb

Although the MANOVA identified an effect of $\operatorname{limb}(p=0.024)$, the univariate tests exhibited this effect only in the AP direction $(p=0.005)$. The toe-off velocity in the AP direction was larger for the non-dominant than the dominant limb (Table 2).

Leading Limb

The MANOVA identified an effect of limb $(p=0.002)$, and the univariate test showed this effect in both AP ( $\leq \leq 0.0001)$ and vertical $(p=0.005)$ directions. In both directions, the toe-off velocity was higher for the non-dominant than for the dominant limb (Table 2). 
Brazilian Journal of Motor Behavior

Table 2 - Mean and standard deviation (in brackets) for the foot toe-off velocity of the trailing and leading limbs. The two right columns indicate the differences observed in the statistical analyses.

\begin{tabular}{|c|c|c|c|c|}
\hline \multicolumn{5}{|c|}{ MANOVA \& } \\
\hline & Dominant & $\begin{array}{c}\text { Non- } \\
\text { Dominant }\end{array}$ & Univariate Tests & Differences \\
\hline \multicolumn{5}{|l|}{ Trailing Limb } \\
\hline \multicolumn{3}{|c|}{ Toe-off Velocity $(\mathrm{m} / \mathrm{s})$} & $\begin{array}{c}\text { Wilks' } \lambda=0.660 \\
F_{2,18}=4.646, p=0.024\end{array}$ & \multirow{3}{*}{$\begin{array}{c}\text { Non Dominant }> \\
\text { Dominant }\end{array}$} \\
\hline AP Direction & $\begin{array}{c}0.303 \\
(0.162)\end{array}$ & $\begin{array}{c}0.466 \\
(0.230)\end{array}$ & $F_{1,19}=9.805, p=0.005$ & \\
\hline Vertical Direction & $\begin{array}{c}0.265 \\
(0.083)\end{array}$ & $\begin{array}{c}0.299 \\
(0.096)\end{array}$ & $F_{1,19}=1.460, p=0.242$ & \\
\hline \multicolumn{5}{|l|}{ Leading Limb } \\
\hline \multicolumn{3}{|c|}{ Toe-off Velocity $(\mathrm{m} / \mathrm{s})$} & $\begin{array}{c}\text { Wilks' } \lambda=0.498, \\
F_{2,18}=9.072, p=0.002\end{array}$ & \multirow{3}{*}{$\begin{array}{c}\text { Non Dominant }> \\
\text { Dominant } \\
\text { Non Dominant }> \\
\text { Dominant }\end{array}$} \\
\hline AP Direction & $\begin{array}{c}0.078 \\
(0.099)\end{array}$ & $\begin{array}{l}0.456 \\
(0.341)\end{array}$ & $\begin{array}{c}F_{1,19}=18.687 \\
\mathbf{p} \leq 0.0001\end{array}$ & \\
\hline Vertical Direction & $\begin{array}{c}0.131 \\
(0.219)\end{array}$ & $\begin{array}{c}0.364 \\
(0.247)\end{array}$ & $F_{1,19}=9.896, p=0.005$ & \\
\hline
\end{tabular}

AP: anterior-posterior direction

Bold p-values indicate a significant effect of limb.

\section{Spatiotemporal gait parameters \\ Training Limb}

The ANOVA exhibited a main effect of limb for stride length $(p=0.022)$ and stride speed $(p=0.006)$. Both variables were larger for the non-dominant than for the dominant limb (Table 3). The ANOVA did not identify an effect of limb for the stride duration.

\section{Leading Limb}

The ANOVA did not identify an effect of limb for any of the variables (Table 3).

Table 3 - Mean and standard deviation (in brackets) for the stride length, duration, and speed of the trailing and leading limbs. The two right columns indicate the differences observed in the statistical analyses.

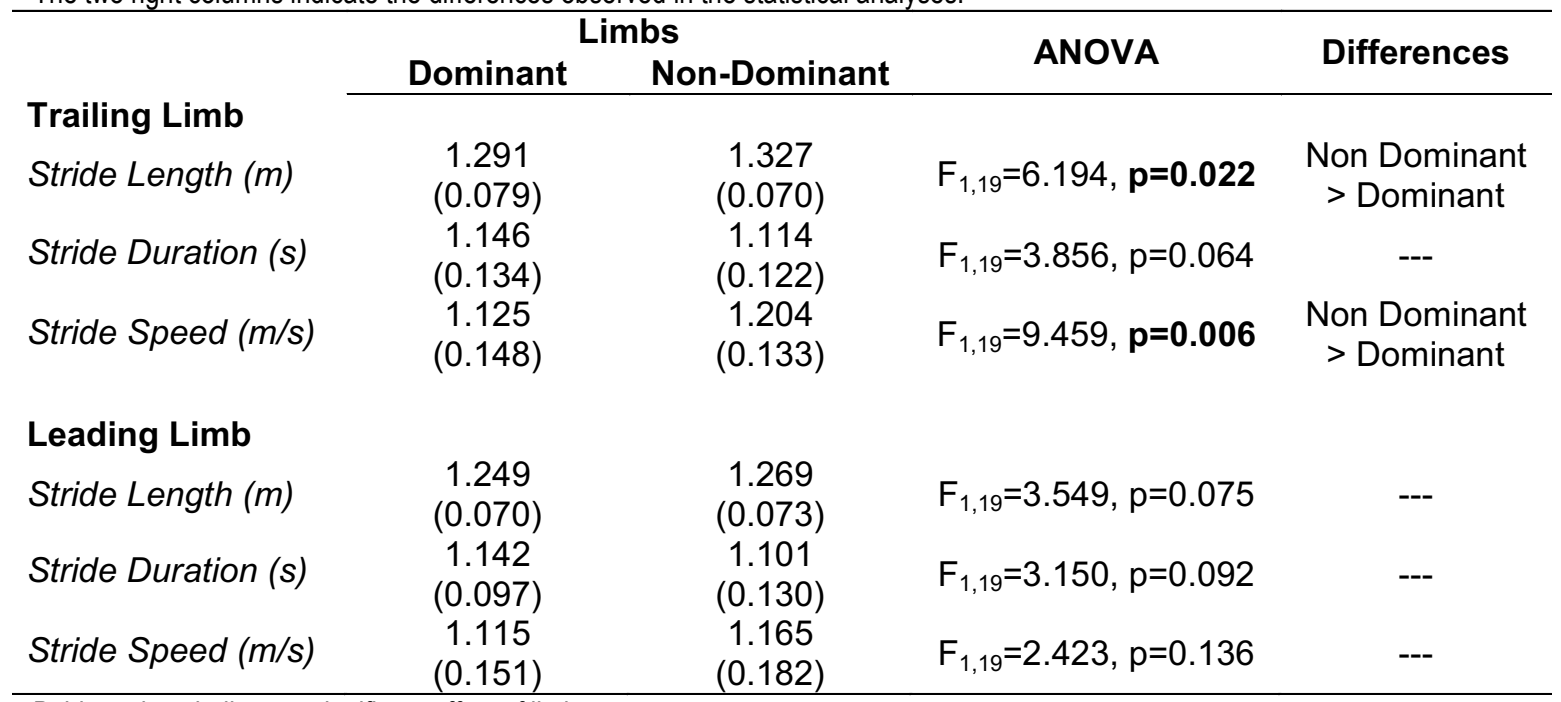

Bold p-values indicate a significant effect of limb. 


\section{DISCUSSION}

We investigated the effect of lower limb dominance on walking adaptations in the presence of a hole in the ground. For the trailing limb, the impulses were not affected by the lower limb dominance, but for the leading limb, the non-dominant limb increased the braking and propulsive impulses compared to the dominant limb. On the other hand, the toe-off velocity of both trailing and leading limbs was affected by lower limb dominance. Toe-off velocity increased when the non-dominant limb was used as trailing and leading limbs. Spatiotemporal gait parameters were affected by limb dominance only for the trailing limb. In addition, all the participants successfully performed the task of stepping into the hole and none of them stumbled on the borders of the hole. The meaning of these findings is discussed below.

For the trailing limb, three important changes occurred when this limb was the non-dominant one; individuals increased the toe-off velocity, in addition to increasing stride length and speed. These changes are directly linked to gait progression and increased safety. The increase in toe-off velocity favored a longer stride length and speed. This longer stride length can be seen as a mechanism to increase safety while the dominant limb is dealing with the hole. It increases the base of support in the AP direction, which can help to avoid a fall if the dominant leg stumbles on the edge of the hole when leaving it. These findings support our hypothesis and agree with the argument that the non-dominant limb is better for providing support while the dominant limb is moving towards a goal. ${ }^{12,20}$

For the leading limb, the AP braking and propulsion impulses were higher for the non-dominant limb than for the dominant one. These changes indicate a greater need to slow down the movement followed by a higher thrust to leave the hole when stepping with the non-dominant limb. Peterson et al. positively correlated braking and propulsion impulses with walking velocity. ${ }^{22}$ Accordingly, in the present study, there was greater variation in velocity between the start and end of the support phase because of the increase in braking and propulsion impulses, which may place the individual at a higher risk of stability disturbance when using the non-dominant limb to step into the hole. These findings suggest a less careful movement, since higher propulsion impulse in the AP direction may compromise the foot exit from the hole. As a consequence, it may place the individual at a higher risk of stumbling when stepping into the hole with the non-dominant limb. Again, these findings agree with our hypothesis that the dominant leg is better for performing actions towards a goal.

Studies on lower limb dominance present controversial results about the relationship between the asymmetry of parameters and dominance of lower limbs during gait.20Some results suggest that the asymmetry found in the lower limbs may be related to their functionality during walking. While the dominant limb contributes more to walking progression, the non-dominant limb contributes more to providing support for the walking task, especially when the task is unilateral. ${ }^{20}$

Our results showed differences between the dominant and non-dominant limbs when they were used to step into the hole or to provide support for the action. The differences found in our study reinforce the idea that asymmetry between the limbs during walking seems to be related to the function they perform, and this becomes more evident in adaptive locomotion. Moreover, these findings may explain the preference of the individuals to step with the dominant limb into the hole. Finally, it is worth noting that in our 
study, the participants were young and the hole used had no restricted dimensions. These characteristics may have facilitated the movement and masked some of the changes when using the non-dominant limb to step into the hole.

Gait speed is an important parameter that can influence walking performance in the task investigated in the present study. It relates to safety, since a reduction in speed contributes to movement accuracy. ${ }^{23}$ In the present study, the movement of the leading limb required accuracy so that the individual would step into the hole and maintain the forward progression. There was no difference between dominant and non-dominant limbs for stride speed. Thus, the demand for accuracy may have contributed to the absence of differences between the limbs when stepping into the hole.

\section{LIMITATIONS}

The depth and length of the hole could influence the adaptations observed in the present study. Thus, since we used fixed dimensions for the hole, future studies should analyze stepping into holes of different depths and lengths to better understand the adaptations in walking when stepping into a hole.

\section{CONCLUSION}

Our results were consistent with asymmetrical behavior between dominant and non-dominant lower limbs. However, the differences found in our study between dominant and non-dominant limbs did not affect success in the task.

\section{REFERENCES}

1. Patla AE. Strategies for dynamic stability during adaptive human locomotion. IEEE Engineering in Medicine and Biology. 200;22:48-52.

https://doi.org/10.1109/MEMB.2003.1195695

2. Moraes R. A model for selecting alternate foot placement during human locomotion. Psychology \& Neuroscience. 2014;7:319-329. http://dx.doi.org/10.3922/j.psns.2014.038

3. Patla AE. Visual control of human locomotion. Advances in Psychology. 1991;78:55-97. https://doi.org/10.1016/S0166-4115(08)60738-4

4. Patla AE, Prentice SD, Rietdyk S, Allard F, Martin C. What guides the selection of alternate foot placement during locomotion in humans. Experimental Brain Research. 1999;128:441-450. https://doi.org/10.1007/s002210050867

5. Weerdesteyn V, Nienhuis B, Hampsink B, Duysens J. Gait adjustments in response to an obstacle are faster than voluntary reactions. Human Movement Science. 2004;23:351-363. https://doi.org/ 10.1016/j.humov.2004.08.011

6. Weerdesteyn V, Nienhuis B, Mulder T, Duysens J. Older women strongly prefer stride lengthening to shortening in avoiding obstacles. Experimental Brain Research. 2005;161:39-46. https://doi.org/ 10.1007/s00221-004-2043-6 
7. Moraes R, Lewis MA, Patla AE. Strategies and determinants for selection of alternate foot placement during human locomotion: influence of spatial and temporal constraints.

Experimental Brain Research. 2004;159:1-13. https://doi.org/10.1007/s00221-004-1888-z

8. Moraes R, Allard F \&Patla AE. Validating determinants for an alternate foot placement selection algorithm during human locomotion in cluttered terrain. Journal of Neurophysiology. 2007; 98:1928-1940. https://doi.org/10.1152/jn.00044.2006

9. Potocanac Z, Duysens J. Online adjustments of leg movements in healthy young and old. Experimental Brain Research. 2017;235:2329-2348. https://doi.org/10.1007/s00221-0174967-7

10. Costa AAS, Santos LO, Moraes R. Effect of a cognitive task on online adjustments when avoiding stepping on an obstacle and stepping on a target during walking in young adults. Experimental Brain Research. 2018;236:2387-2397. https://doi.org/10.1007/s00221-0185310-7

11. Moraes R, Patla AE. Determinants guiding alternate foot placement selection and the behavioral responses are similar when avoiding a real or a virtual obstacle. Experimental Brain Research. 2006;171:497-510. https://doi.org/10.1007/s00221-005-0297-2

12. Sadeghi H. Local or global asymmetry in gait of people without impairments. Gait and Posture. 2003;17:197-204. https://doi.org/10.1016/S0966-6362(02)00089-9

13. Nagano H, Begg RK, Sparrow WA, Taylor S. Ageing and limb dominance effects on footground clearance during treadmill and overground walking. Clinical Biomechanics. 2011;26:962-968. https://doi.org/10.1016/j.clinbiomech.2011.05.013

14. Rocha ES, Machado AS, Franco PS, Guadagnin EC, Carpes FP. Gait asymmetry during dual-task obstacle crossing in the young and elderly. Human Movement. 2013;14(2):138143. https://doi.org/10.2478/humo-2013-0016

15. Hoogkamer W, Potocanac Z, Duysens J. Quick foot placement adjustments during gait: direction matters. Experimental Brain Research. 2015;233:3349-3357. https://doi.org/10.1007/s00221-015-4401-y

16. Laroche DP, Cook SB, Mackala K. Strength asymmetry increases gait asymmetry and variability in older women. Medicine and Science in Sports Exercise. 2012;44:2172-2181. https://doi.org/10.1249/MSS.0b013e31825e1d31

17. Guadagnin EC, Barbieri FA, Simieli L, Carpes FP. Is muscular and functional performance related to gait symmetry in older adults? A systematic review. Archives of Gerontology and Geriatrics. 2019;84:103899. https://doi.org/10.1016/j.archger.2019.103899

18. Muller R, Tschiesche K, Blickhan R. Kinetic and Kinematic adjustments during perturbed walking across visible and camouflaged drops in ground level. Journal of Biomechanics. 2014;47:2286-2291. https://doi.org/10.1016/j.jbiomech.2014.04.041

19. Aminiaghdam S, Blickhan R, Muller R, Rode C. Posture alteration as a measure to accommodate uneven ground in able-bodied gait. PLoS ONE. 2017;12:1-17. https://doi.org/10.1371/journal.pone.0190135 
Brazilian Journal of Motor Behavior

20. Sadeghi H, Allard P, Prince F, Labelle H. Symmetry and limb dominance in able-bodied gait: a review. Gait and Posture. 2000;12:34-45. https://doi.org/10.1016/S09666362(00)00070-9

21. Elias LL, Brydent MP, Bulman-Fleming MB. Footedness is a better predictor than is handedness of emotional lateralization. Neuropsychologia. 1998;36:37-43. http://dx.doi.org/10.1016/S0028-3932(97)00107-3

22. Peterson CL, Kautz SA, Neptune RR. Braking and propulsive impulses increase with speed during accelerated and decelerated walking. Gait and Posture. 2011;33:562-567. https://doi.org/ 10.1016/j.gaitpost.2011.01.010

23. Peper CL, de Dreu MJ, Roerdink M. Attuning one's steps to visual targets reduces comfortable walking speed in both young and older adults. Gait and Posture. 2015;41:830834. https://doi.org/10.1016/j.gaitpost.2015.02.016

\section{ACKNOWLEDGMENTS}

The authors would like to thank Eduardo Bergonzoni Junqueira for helping with data collection and Tenysson Will de Lemos for helping with some of the data processing.

Citation: Santos LO, Costa AAS, Moraes R. Effect of lower limb dominance on walking adaptations in young adults when stepping into a hole. BJMB. 2019: 13(5): 133-143.

Editors: Dr Fabio Augusto Barbieri - São Paulo State University (UNESP), Bauru, SP, Brazil; Dr José Angelo Barela São Paulo State University (UNESP), Rio Claro, SP, Brazil; Dr Natalia Madalena Rinaldi - Federal University of Espírito Santo (UFES), Vitória, ES, Brazil.

Copyright:@ 2019 Santos, Costa and Moraes and BJMB. This is an open-access article distributed under the terms of the Creative Commons Attribution-Non Commercial-No Derivatives 4.0 International License which permits unrestricted use, distribution, and reproduction in any medium, provided the original author and source are credited. Funding: This study was financed in part by the Coordenação de Aperfeiçoamento de Pessoal de Nível Superior Brazil (CAPES) - Finance Code 001.

Competing interests: The authors have declared that no competing interests exist.

DOl: https://doi.org/10.20338/bjmb.v13i5.141 